\title{
Cellular SiC/Iron Alloy Composite
}

\author{
Barbara Lipowska ${ }^{1, *}$, Bronisław Psiuk, Mirosław Cholewa² \\ ${ }^{1}$ Institute of Ceramics and Building Materials Refractory Materials Division, Toszecka 99, Gliwice, 44-100, Poland \\ ${ }^{2}$ Silesian University of Technology, Department of Foundry Engineering, Towarowa 7, Gliwice, 44-100, Poland
}

*Corresponding author: E-mail: b.lipowska@icimb.pl; Tel: (+48) 322701955

DOI: 10.5185/amlett.2020.061530

Cellular SiC/iron alloy composite with a spatial structure of mutually intersecting skeletons created with a porous ceramic preform has not been obtained before, despite promising spectrum of potential uses. We tested the possibility of obtaining such material using a SiC material with an oxynitride bonding and grey cast iron. Porous ceramic preforms were made by pouring the gelling ceramic suspension over a foamed polymer base which was next fired. The obtained samples of materials were subjected to macroscopic and microscopic observations as well as investigations into the chemical composition in microareas. It was found that the minimum width of a channel in the preform, which in the case of pressureless infiltration enables molten cast iron penetration, ranges from 0.10 to $0.17 \mathrm{~mm}$. It was also found that the ceramic material applied was characterized by good metal wettability. Were the channels are wide enough for the metal penetration we observed that the ceramics/metal contact area always has a transition zone in which mixing of both components takes place.

\section{Introduction}

At the core of research on ceramic/metal composites are attempts to develop a casting technology for machine elements and devices working in intensive abrasive wear conditions.

It is known that composite can be defined as a combination of two inherently different materials that gains properties exceeding these of the constituent materials. In case of the ceramic-metal composites they can exceed properties of both ceramics and metal. Such a composite can have a higher fracture toughness and higher resistance to thermal shock. At the same time they have a higher hardness and rigidness, higher resistance to trybological wear and lower creep at elevated temperatures than metal $[1,2]$.

Ex-situ and in-situ techniques are most common in obtaining dispersed composites. The ex-situ techniques usually involve mechanical mixing of molten metal with simultaneous addition of ceramic particles, or molten metal infiltration into a densely packed layer of particles or fibres $[\mathbf{3}, \mathbf{4}]$. As a result, a non-continuous ceramic reinforcing phase dispersed in the homogenous matrix of the metal is obtained.

Alternatively, composites can be produced in a form of mutually penetrating matrices of the ceramic and metal phase. This structure allows the components of the composite to compliment properties of one another more efficiently than in composites with a dispersed ceramic phase [5-9].

Ceramic-metal composites with interpenetrating networks structure can be obtained by infiltration of previously prepared porous ceramic preforms with molten metal. The preparation of this kind ceramic material can be carried out by e.g. by sintering the fractionated grains [1014], gelling a foamed ceramic suspension $[6,8,15-17]$ or using open-cell polymer foam.

The last method can be implemented in two ways. The first of these consists in impregnating the polymer foam with a polymodal suspension containing ceramic particles in such a way that only the bridges surrounding the pores in the foam are covered $[\mathbf{9}, \mathbf{1 8}]$. The second way consists of full flooding of the polymer foam with a ceramic suspension and subsequent firing of the organic matrix [19].

Proper connection between the metal and ceramic phases is an important factor for both the dispersed and continuous forms of composites, as it determines the quality of load transfer between components. The connection depends mainly on the ceramic surface wettability by the molten metal [20-22]. Insufficient wettability can be particularly problematic when creating composites through pressureless infiltration of porous preform [23].

Another aspect of the ceramic-metal joint is its durability. This is determined by the structure of the division surface, which can be mechanical (mutual anchoring of materials), adhesive (intermolecular forces of the adhering phases) or diffusive (mixing of both phases' components, which may also result in the formation of a new phase) [7].

The most widely studied are composites based on light alloys containing $\mathrm{Al}_{2} \mathrm{O}_{3}, \mathrm{SiC}$ or $\mathrm{SiO}_{2}$ particles. They are used especially in the automotive or aerospace industries $[3,24-26]$. Research is also being carried out on obtaining composites with an aluminium alloy matrix by infiltration of molten metal into ceramic alumina preforms in the form of foams $[6,8,27]$. 


\section{Advanced Materials Letters www. vbripress.com/aml}

Composites based on iron alloys are not studied so well because of technological difficulties, mainly due to the temperature of the molten metal which is much higher than the typical melting temperature for $\mathrm{Mg}$ or $\mathrm{Al}$ alloys. However, the modern mining and mineral industry is interested in these types of materials. Due to the good combination of hardness, stiffness, wear resistance and corrosion of ceramics with ductility and fracture toughness of metal phase, ceramic-metal composites with iron metal matrix can be used as elements of machines and devices operating in conditions of intensive abrasive wear. In cases of steel alloy/ceramic composites, the reinforcing phase typically consists of sintered $\mathrm{Al}_{2} \mathrm{O}_{3}, \mathrm{TiC}$, TiN or $\mathrm{ZrO}_{2}$ grains $[12,13,23,28,29]$.

Here we want to present the results of preliminary tests aimed at obtaining a cellular SiC/iron alloy composite with a spatial structure of mutually intersecting networks through pressureless infiltration of porous ceramic preform with molten metal. The microstructure of the obtained composite sample is characterized. The contact between $\mathrm{SiC}$ and cast iron is analysed too.

\section{Experimental}

\section{Manufacture of porous ceramic preforms}

In the research, an open-cell polymer foam was used to obtain a porous ceramic preform. First, samples of polyurethane foam (Eurofoam, Poland) with a porosity of $10 \mathrm{ppi}$ and dimensions of $20 \times 20 \times 40 \mathrm{~mm}$ were prepared (Fig. 1). These samples were filled with a gelling slurry [30] containing:

- ceramic particles SiC F1000 (Carborex - Washington Mills) with the grain size $\mathrm{d}_{50}=4,5 \pm 0,8 \mu \mathrm{m}$ and chemical composition: $\mathrm{SiC} 98.3 \%, \mathrm{C} 0.25 \%, \mathrm{Si} 0.35 \%$, $\mathrm{SiO}_{2} 0.6 \%$, Fe 0.1\%;

- $\quad$ silica sol (Rudniki S.A., Poland) as a binder;

- $\mathrm{NH}_{4} \mathrm{Cl}$ (Chempur, Poland) as a gelling agent.

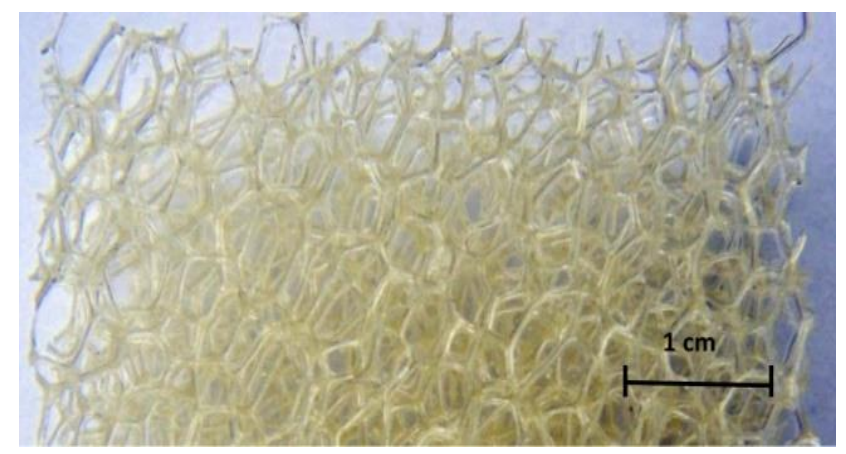

Fig. 1. Polyurethane foam with the porosity of 10 ppi.

After gelling, the preforms were heat treated at $600^{\circ} \mathrm{C}$ in air atmosphere. In such conditions, the foam burns out completely and a porous material is obtained with open channels that replicate the original polymer foam structure.

In order to widen the channels, some tests involved polymer foams with struts thickened by covering them with a suspension containing 50\% wt. organic binder (Osacryl OSA NM - Synthos Dwory) and 50\% wt. carbonaceous resin powder (Carbores $\mathrm{P}$ - Rütgers), which was then completely burnt in $600^{\circ} \mathrm{C}$.

The next step was firing the preforms in $1400^{\circ} \mathrm{C}$ in nitrogen atmosphere, which provided a porous material with $\mathrm{SiC}$ on an oxynitride bonding (Fig. 2 and Table 1).

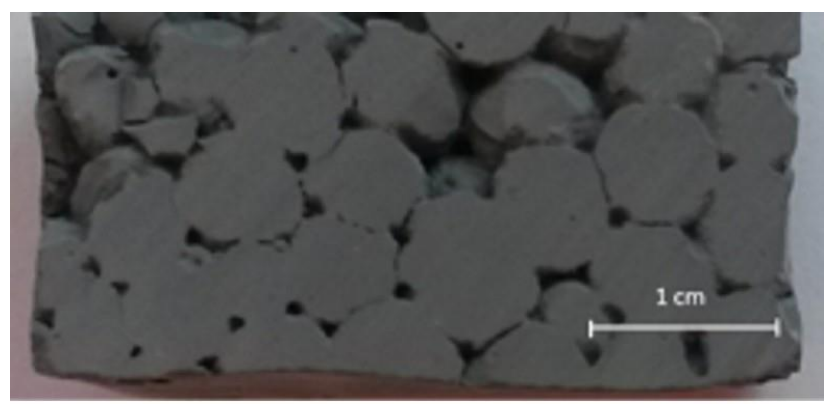

Fig. 2. Cross-section of a porous SiC preform.

Table 1. Basic physical and chemical properties of a porous material with $\mathrm{SiC}$ on an oxynitride bonding.

\begin{tabular}{l|c|c}
\hline \multicolumn{1}{c|}{ Determination } & Unit & Value \\
\hline Apparent density & $\mathrm{g} / \mathrm{cm}^{3}$ & 1,69 \\
\hline Open porosity & $\%$ & 40,3 \\
\hline Flexural strength & $\mathrm{MPa}$ & 35,3 \\
\hline Basic components content: & $\%$ & 82,6 \\
$\mathrm{SiC}$ & $\mathrm{SiO}_{2}$ & 17,0 \\
\hline Phase composition: & \\
$\mathrm{SiC}^{2}$ & \\
$\mathrm{Si}_{2} \mathrm{~N}_{2} \mathrm{O}$ (sinoite) & \\
$\mathrm{SiO}_{2}$ (cristobalite) & \\
\hline
\end{tabular}

\section{Molten metal infiltration of preforms}

After firing, the preforms were placed in a casting mould made of synthetic quartz mass with bentonite and filled with molten grey cast iron at the temperature of $1590^{\circ} \mathrm{C}$. Chemical composition of the grey cast iron: $\mathrm{C} 3.06 \%, \mathrm{Si}$ $2.38 \%$, Mn $0.32 \%$, P $0.03 \%$, Cr $0.31 \%$, Ni $0.18 \%$, Mo $0.37 \%, \mathrm{Cu} 0.20 \%$.

The obtained samples of materials were subjected to macroscopic and microscopic observations as well as investigations into the chemical composition in microareas by means of a Mira 3 scanning electron microscope, produced by Tescan, equipped with an EDS spectroscope (Aztek system produced by Oxford Instruments).

\section{Discussion of results}

Discussing the results of the preliminary research presented below it should be emphasized that these are only preliminary attempts. Therefore, they should not be treated as complete and accurate from the point of view of the technology being developed.

The samples of composites obtained during the preliminary tests have been subjected to macro and microscopic evaluation.

Based on the macroscopic observation of the obtained material samples cross-sections it was found, that the preforms without strut thickening were not infiltrated, whereas extension of the channels allowed the molten metal permeation (Fig. 3). 


\section{Advanced Materials Letters www. vbripress.com/aml}

(a)

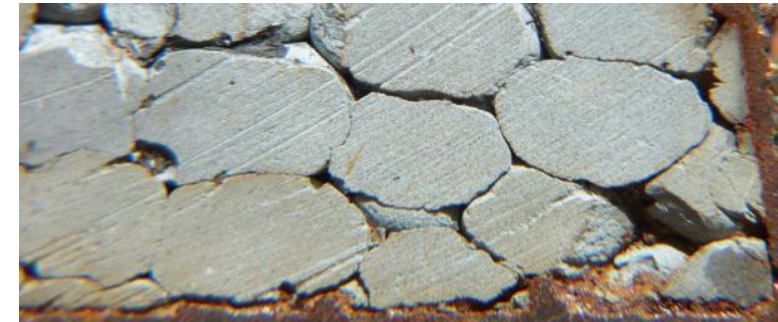

(b)

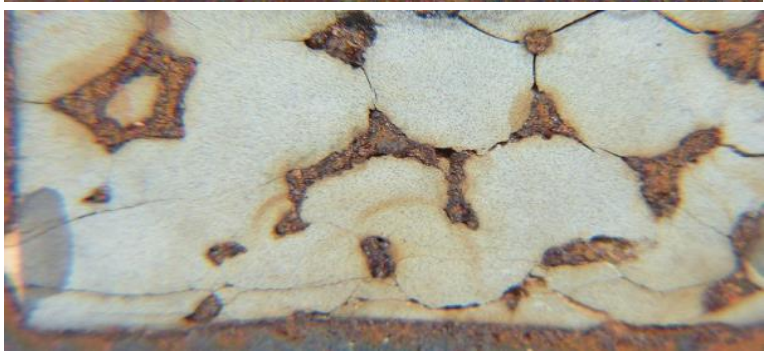

Fig. 3. Macrostructure of the composite sample cross-section: (a) preform without extended channels, (b) preform with extended channels.

The microscopic image of the composite sample crosssection (Fig. 4a) indicates that the channels having a minimum dimension of $0.17 \mathrm{~mm}$ were infiltrated, whereas metal did not permeate into channels with the dimension lower than $0.1 \mathrm{~mm}$. It was also found that the ceramic material applied was characterized by good metal wettability. The ceramics-metal connection was compact without visible cracks.

(a)

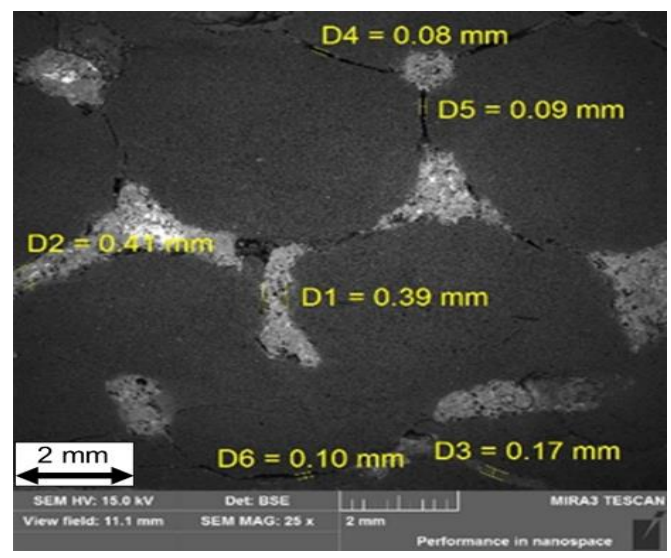

(b)

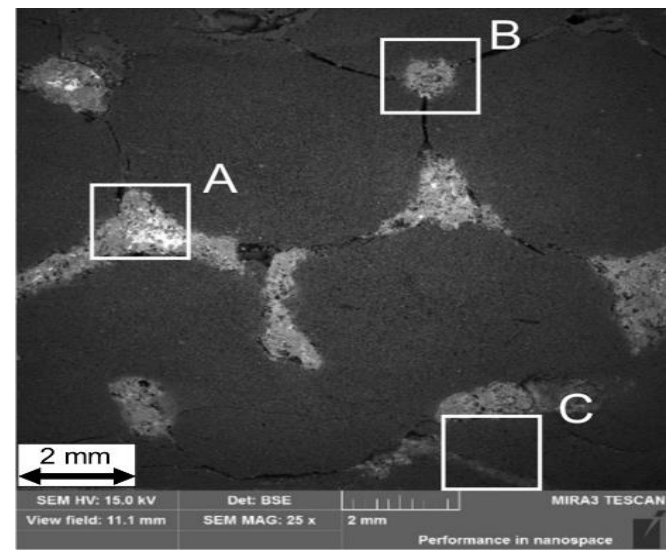

Fig. 4. Microstructure of the composite sample cross-section: (a) dimension of channels in the preform, (b) selected areas of infiltration subjected to analysis.
The microscopic observations of selected areas of infiltration (A, B and C in Fig. 4b) also revealed (Fig. 5-7) that they were not homogenous, forming a transition zone between the components. Based on the analysis of elements' distribution in the microareas, it can be concluded that this transition zone is formed due to the process of mixing the metal components and the ceramic material.

It was confirmed by chemical composition analysis of changes for main components - Si and Fe along the set line (linear profiles present changes for $\mathrm{Si}$ and $\mathrm{Fe}$ - main components of the composite in ceramics and metal, respectively). Fluctuation of $\mathrm{Si}$ and $\mathrm{Fe}$ contents in the transition zone suggests that it takes place when the components of the ceramic phase and metal are mechanically mixed.

The transition zone thickness is changeable, ranging from 30 to $120 \mu \mathrm{m}$ in the areas subjected to observation (Fig. $5 \&$ 6). If the infiltration area is narrower than this range, it already contains components characteristic of the transition zone and the region of pure metal is absent (Fig. 7).

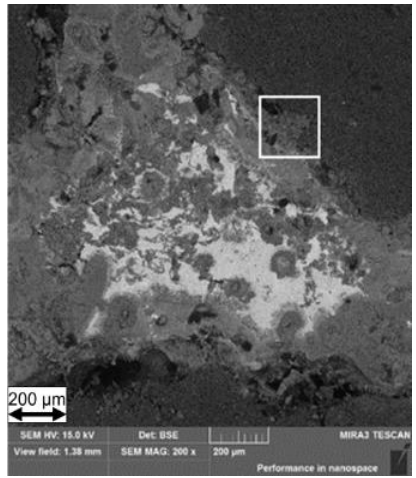

(a)

(c)

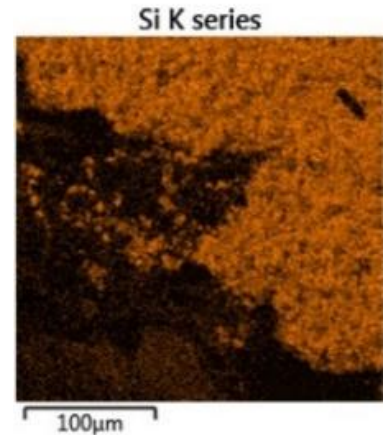

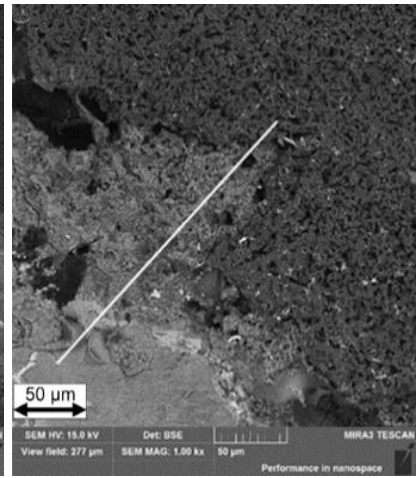

(b)

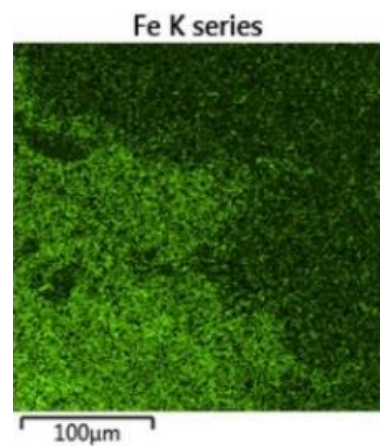

(d)

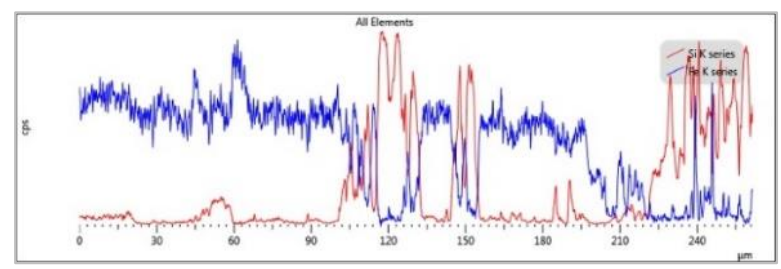

Fig. 5. Area A - BSE micrographs of magnification: a) 200x, b) 1000x and analysis of chemical composition in microareas: c) distribution of $\mathrm{Si}$ and $\mathrm{Fe}$, d) linear profiles of $\mathrm{Si}$ and $\mathrm{Fe}$ contents drew perpendicular to the ceramic-metal contact line. 


\section{Advanced Materials Letters www. vbripress.com/aml}

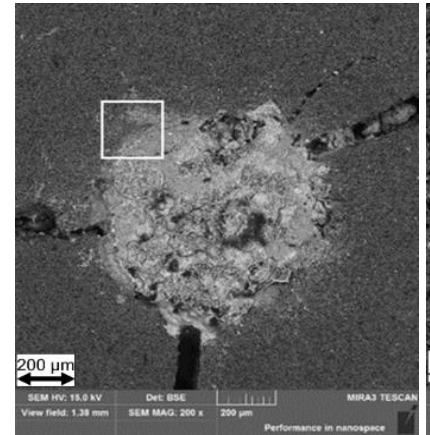

(a)

(c)

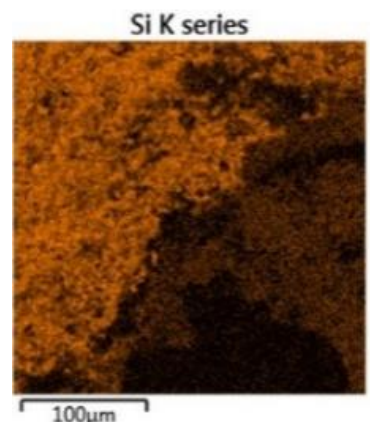

(d)

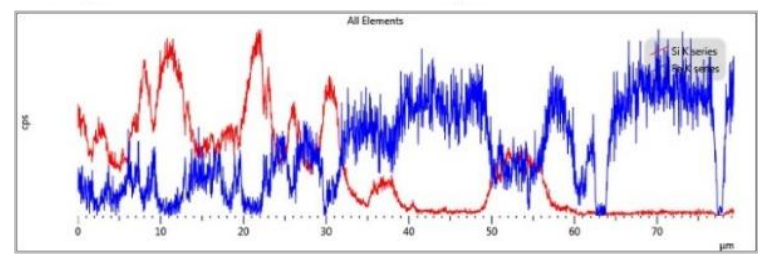

Fig. 6. Area B - BSE micrographs of magnification: a) 200x, b) 1000x and analysis of chemical composition in microareas: c) distribution of $\mathrm{Si}$ and $\mathrm{Fe}$, d) linear profiles of $\mathrm{Si}$ and $\mathrm{Fe}$ contents drew perpendicular to the ceramic-metal contact line.

Another important property of the discussed area is its compactness. We did not observe cracks at the border between the ceramic grains and the metal surrounding them. The occurrence of physical and chemical reactions can therefore be assumed during the creation of the transition phase, which causes the formation of new phases at the ceramic / metal interface. This observation confirms the good wettability of ceramic grains with molten metal.

The results of the above experiments are the basis for our further studies, which are currently ongoing. They consist in replacing the polymer foam with a form created by means of FDM 3D spatial printing technology, which allows control over strut width and spatial organization. This method should ensure good metal infiltration and more predictable composite structure. The results of the preliminary studies of this material are not yet sufficient for a publication but were presented on the 26th assembly of Advanced Materials Congress (AMC) held during 10-13 June 2019.

In this article we presents only results from our tests aimed at obtaining an SiC/iron alloy composite in a form of mutually penetrating matrices using a method of pressureless metal infiltration into a porous ceramic shape. Details determination of the dominant connection in the presented composite will be the subject of further investigations. Nevertheless the presented results prove the methodological possibility of obtaining a composite of expected structure and composition.

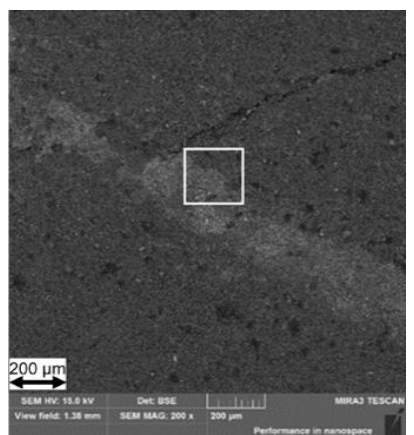

(a)

(c)

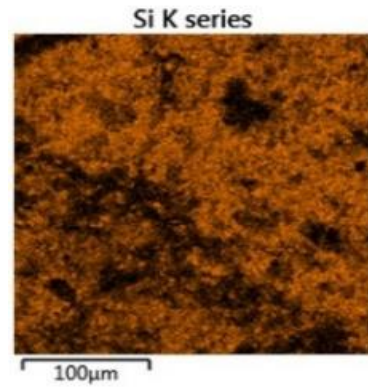

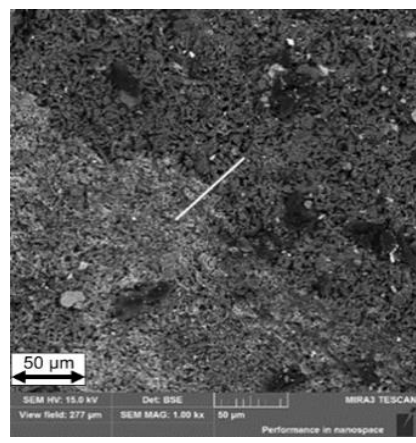

(b)

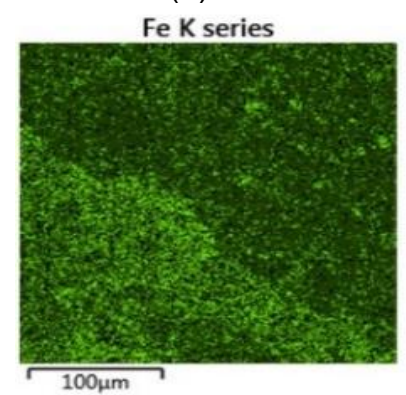

(d)

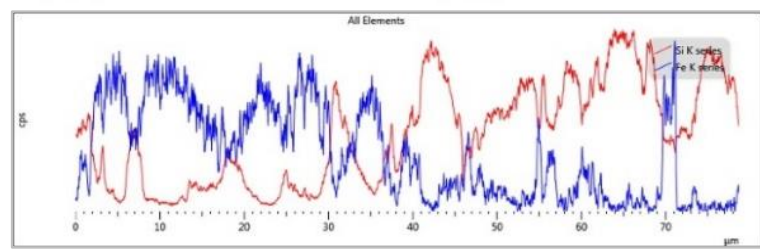

Fig. 7. Area C - BSE micrographs of magnification: a) 200x, b) 1000x and analysis of chemical composition in microareas: c) distribution of $\mathrm{Si}$ and $\mathrm{Fe}$, d) linear profiles of $\mathrm{Si}$ and $\mathrm{Fe}$ contents drew perpendicular to the ceramic-metal contact line.

\section{Summary}

We confirmed a possibility of obtaining a composite in a form of mutually intersecting sceletons using a $\mathrm{SiC}$ material with an oxynitride bonding and grey cast iron material.

Our research conducted using porous preforms with channel structure determined by a polymer foam indicated pressureles molten metal infiltration into channels wider than $0.10 \mathrm{~mm}$

The ceramics/metal contact area always has a transition zone (when the channel width is big enough), where mixing of the components of both composite elements takes place.

As already mentioned at the beginning of the discussion on the results, the presented observations are indeed preliminary. Necessary for the full assessment of the obtained composite materials will be checking the mechanical properties of the developed ceramic-metal composite e.g.: strength test to determine the Young's modulus, impact strength of the material and tribological tests 


\section{Advanced Materials Letters \\ www. vbripress.com/aml}

\section{Acknowledgements}

This work has been financed from the resources for the statutory activity of the Institute of Ceramics and Building Materials - Refractory Materials Division in Gliwice.

\section{Keywords}

Ceramic-metal composites, porous ceramics, cast iron, silicon carbide.

Received: 30 April 2019

Revised: 16 July 2019

Accepted: 23 October 2019

\section{References}

1. Rosso, M.; J. Mater. Process. Tech., 2006, 175, 364.

2. Akhtar, F.; Can. Metall. Q., 2014, 53, 253.

3. Ibrahim, I.A.; Mohamed, F.A.; Lavernia, E. J.; J. Mater. Sci., 1991, 26, 1137.

4. Raether, F.; Ceram. Appl., 2013, 1, 45.

5. Clarke, D.R.; J. Am. Ceram. Soc., 1992, 75, 739.

6. Binner, J.; Chang, H.; Higginson, R.; J. Eur. Ceram. Soc., 2009, 29 , 837.

7. Szafran, M.; Rokicki, G.; Lipiec, W.; Konopka, K.; Kurzydłowski, K.; Composites, 2002, 2, 313.

8. Mattern, A.; Huchler, B.; Staudenecker, D.; Oberacker, R.; Nagel, A.; Hoffmann, M.J; J. Eur. Ceram. Soc., 2004, 24, 3399.

9. Shouren, W.; Haoran, G.; Jingchun, Z.; Yingzi, W.; Appl. Compos. Mater., 2006, 13), 115.

10. Konopka, K.; Szafran, M.; J. Mater. Process. Tech., 2006, 5, 266.

11. Konopka, K.; Olszówka-Myalska, A.; Szafran, M.; Mater Chem Phys, 2003, 81, 329.

12. Dulska, A; Studnicki, A.; Szajnar, J.; Arch. Metall. Mater., 2017, 1, 355.

13. Witting, D.; Aneziris, C.G.; Graule, T.; J. Mat. Sci., 2009, 44, 572.

14. Rödel, J.; Anales de Macánica del la Fractura, 2002, 19, 13.

15. Lemster, K.; Delporte, M.; Graule, T.; Kuebler, J.; Ceram. Int., 2007, 33,1179 .

16. Chang, H.; Higginson, R.; Binner, J.; J. Mat. Sci., 2010, 45(3), 662.

17. Potoczek, M.; Myalski, J.; Śleziona, J.; Śliwa, R.E.; Inż. Mat., 2009, 30, 536.

18. Dulska, A; Studnicki, A.; Cholewa, M.; Szajnar, J.; Arch. Foundry Eng., 2018, 18, 137.

19. Lange, F.F.; Velamakanni, B.V.; Evans, A.G.; J. Am. Ceram. Soc., 1990, 73, 388 .

20. Nogi, K.; Scripta Mater., 2010, 62, 945.

21. Pagounis, E.; Talvitie, M.; Lindroos, V.K.; Compos Sci Technol, 1996, 56, 1329.

22. Bǔlǐč, I.; Gürü, M.; Tekelĭ, S.; GU J. Sci., 2015, 28, 295.

23. Krauß, G.; Kübler, J.; Trentini, E.; Mat. Sci. Eng. A - Struct., 2002, $337,315$.

24. Sobczak, J.; Wojciechowski, S.; Composites, 2002, $2,24$.

25. Alam, Md. T.; Ansari, A.H.; IFJ, 2014, 60, 25.

26. Mohanakumara, K.C.; Rajashekar, H.; Ghanaraja, S.; Ajitprasad, S.L.; Procedia Materials Science, 2014, 5, 934.

27. Myalski, J.; Hekner, B.; Inż. Mat., 2015, 36, 220

28. Čikara, D.; Rakin, M.; Todič, A.; FME Transitions, 2009, 37, 151.

29. Sobula, S.; Olejnik, E.; Tokarski, T.; Arch. Foundry Eng., 2017, 17, 143.

30. Psiuk, B.; Lipowska, B.; Czechowska, K.; Gerle, A.; Stanek, M.; Śliwa, A.; Ceramic Materials, 2017, 69, 243. 